\title{
Play along ou play alone?: um estudo sobre presença e interatividade na livre improvisação musical
}

Play along or play alone?: studies on presence, interactivity and free musical improvisation

Fabio Manzione ${ }^{1}$

Universidade de São Paulo fabio.manzione.ribeiro@usp.br 


\section{Resumo}

Este artigo é composto por reflexões acerca do conceito de produção de presença desenvolvido por Hans Ulrich-Gumbrecht e pela apresentação de procedimentos que visam aproximar o conceito à prática da Livre Improvisação Musical (LIM). Para instaurar o processo criativo associado às concepções de Gumbrecht, foi desenvolvida uma proposta performativa a ser realizada pela Orquestra Errante, grupo que pesquisa a LIM. Dentre seus direcionamentos, a proposta sugere que musicistas improvisem mediadas/os por gravadores de áudio e pela internet $\mathrm{e}$, posteriormente, façam relatos sobre oscilações entre efeitos de sentido e presença que tenham ocorrido durante as improvisações e quais qualidades a presença física trariam para este tipo de performance. 0 estudo buscou, portanto, acrescentar novas ferramentas para a criação sonora em tempo real e propiciar reflexões a respeito das relações unívocas estabelecidas entre suas/seus participantes, seguindo preceitos conceituais apresentados pelo pensamento gumbrechtiano.

Palavras-chave: livre improvisação musical, produção de presença, interatividade virtual, performance, inter- studies.

\section{Abstract}

This article is composed by reflections about the concept of production of presence developed by Hans Ulrich-Gumbrecht and by the presentation of procedures that aim to approximate the concept to the practice of Free Musical Improvisation (FMI). To establish the creative process associated to Gumbrecht\&\#39;s conceptions, a performative proposal was developed to be performed by Orquestra Errante, a group that researches FMI in University of São Paulo (Brazil). Among its directions, the proposal suggests that musicians improvise mediated by audio recorders and internet and then report on oscillations between sense and presence effects that have occurred during improvisations and what qualities physical presence would bring to this type of performance. The study sought, therefore, to add new tools for the creation of sound in real time and to provide reflections on the univocal relationships established between its participants, following conceptual precepts presented by Gumbrecht`s thought.

Keywords: Free musical improvisation; production of presence; virtual interactivity; performance; interdisciplinary disciplinaridades.

\footnotetext{
1 Fabio Manzione é músico, pesquisador e artista-educador. Doutorando em Música pela Universidade de São Paulo e mestre em Estudos de Jazz pela Universidade de Aveiro (Portugal). Em suas pesquisas busca estabelecer vínculos prático-teóricos entre processos de criação sonora em tempo real e outras áreas do conhecimento, bem como analisar a função dos sentidos humanos e da corporalidade em performances que têm 0 som como fundamento. Como percussionista faz parte de grupos que praticam a Livre Improvisação Musical dentro efora do âmbito acadêmico, tais como: Orquestra Errante, Trio Mamomã, Ñembo e Duo Cóz.
} 


\section{Introdução}

Este artigo apresenta o relato de uma proposta performativa autoral concebida para grupos de livre improvisadoras/es. Nele, reflito sobre as experiências elaboradas entre as/os músicas/os da Orquestra Errante - grupo de estudos em Livre Improvisação Musical (LIM) que acolheu meus intentos investigativos - a partir dos conceitos elaborados na obra Produção de presença: o que o sentido não consegue transmitir do teórico alemão Hans Ulrich Grumbrecht.

A Orquestra Errante (OE), fundada em 2009 por Rogério Costa, professor do Departamento de Música da Universidade de São Paulo, desenvolve há anos em seus ensaios semanais o que denomino como uma cultura de propostas. Tais propostas são formadas por estratégias performativas de criação em tempo real oriundas das pesquisas individuais de suas/seus propositoras/es e propiciam o desenvolvimento de materiais sonoros que podem vir a ser utilizados em situações contingenciais futuras. Além disso, podem provocar discussões conceituais realizadas antes ou após as sessões de improvisação musical.

O cultivo destas atividades é, desde a fundação do grupo, algo que compõe os ensaios e oferece às/aos propositoras/es a possibilidade de colocar em prática e à prova trabalhos autorais que dialoguem com as intenções político-estéticas da OE e, consequentemente, com os preceitos da LIM.

No contexto dos ensaios da OE há também uma tentativa constante de estabelecer uma desierarquização das atribuições de cada integrante, sendo validada assim uma dinâmica diversa, fluida e, ainda que a tentativa seja utópica, livre de padrões convencionais de organização coletiva. Estas desconstruções de padrões estético-sonoros buscadas pelo grupo permitem elaborar estudos que não necessitem de predeterminações conceituais associadas aos processos de criação, salvo a ideia de interagir com a/o outra/o e a intenção de criar música livre de precedentes formais, estilísticos, rítmicos ou harmônicos². Por outro lado, há também, em razão desta atitude "desobediente" por parte do grupo, uma abertura para diferentes tipos de formulações conceituais que possam vir a provocar a experimentação de modos de atuação sonora distintos dos já elaborados anteriormente pelas/os participantes da OE.

É importante mencionar que o campo da improvisação musical é bastante vasto e repleto de formulações conceituais e análises sobre sua prática. Em minhas pesquisas, trabalho a partir da ideia de que existem quatro maneiras de se conceber e praticar a improvisação na área da Música, a improvisação idiomática, a improvisação dirigida, a improvisação direcionada e a improvisação livre ${ }^{3}$ sendo as duas últimas as que definem o escopo sobre o qual minha proposta se estabeleceu:

2 Um exemplo disso é o fato do grupo observado estabelecer um ambiente estético apartado do fazer musical que depende da decodificação de códigos visuais para desenvolver seus processos de criação. 0 posicionamento político-estético da $0 E$, assim como de outros grupos que praticam e pensam a LIM, coloca em xeque a utilização de partituras tradicionais ou gráficas compostas em momento diferido. Isto, em virtude das mesmas sugerirem uma série de significados preconcebidos pelo/a compositor/a, conferindo sentido aos gestos corporais da/o performer e à sua sonoridade antes desta/e imprimir sua própria expressão física do som.

3 As improvisações dirigida, direcionada elivre também podem apresentar momentos em que se configuram gêneros musicais preestabelecidos, embora sem possuir os mesmos fins que a improvisação idiomática. 
1) A improvisação idiomática é uma maneira de se improvisar a partir de um gênero musical específico, onde se deve seguir padrões estilísticos, formais, harmônicos, melódicos e rítmicos. O choro, a salsa e o jazz são alguns dos exemplos de gêneros musicais que se utilizam desta espécie de improvisação;

2) A improvisação dirigida é uma prática musical em que não há a necessidade de se improvisar a partir da estrutura de um gênero musical predeterminado (podendo, eventualmente fazer uso de elementos oriundos de contextos idiomáticos), tendo um/a condutor/a como figura central que dirija os momentos de entrada de instrumentos ou naipes, as mudanças de intensidade, nuances timbrísticas, etc. Embora não seja obrigatório improvisar dentro de um estilo ou gênero musical definido durante as sessões de improvisação dirigida, com o estabelecimento da função do condutor nesta prática, a dimensão dos momentos de improvisação/criação de seus instrumentistas é mais reduzida;

3) A improvisação direcionada é uma prática musical em que as/os musicistas podem improvisar sem a necessidade de uma estrutura, gêneros predeterminados ou condutor/a. Ainda assim, devem seguir roteiros e/ou diretrizes relacionais sugeridos antes da prática pelas/os própria/os musicistas ou por pessoas externas ao grupo executante;

4) A improvisação livre é uma prática musical que segue os preceitos de interação, de escuta do ambiente, de experimentação individual e coletiva, de reformulação de padrões técnicos e conceituais vinculados à expressão sonora.

Nos últimos anos, a utilização de procedimentos da comunicação telemática em sessões de LIM tem sido objeto de estudo de minha pesquisa como músico e membro da $\mathrm{OE}$, junto da qual concebi uma proposta fazendo uso de gravadores de áudio e computadores conectados à internet para realizar investigações performativas. O tema está envolvido com a pesquisa que desenvolvo sobre em que proporção os sentidos humanos, que não a escuta, estão imbricados na performance de LIM e como se relacionam as/os musicistas entre si e com seu público durante a prática de criação musical em tempo real.

A LIM, como já dito, opera em um ambiente de experimentação de timbres, técnicas e relações sonoras das mais diversas em prol de uma prática que possa ser desprovida de elementos específicos de tradições musicais eruditas ou populares. Mais precisamente, não necessita se configurar a partir de tonalismos, ostinatos ritmicos preconcebidos, formas ou formações que venham situar o fazer musical dentro de algum gênero já estabelecido. Ademais, durante as práticas de LIM também "coexistem diferentes energias, atitudes singulares, pensamentos, conexões, histórias pessoais e coletivas" (COSTA, 2016, p.39) que conferem a cada sessão qualidade única, não passível de ser repetida por conta de sua proposital efemeridade. Em suma, a LIM se dá a partir da escuta apurada da/o performer sobre si mesmo e em direção ao outro e às experiências que as relações entre músicas e músicos instauram no decorrer da performance, sendo estimulado em suas práticas que apenas fatores contingenciais promovam as mutações sonoras que venham a ocorrer durante as sessões. Além disso, 
Esses processos podem ser realizados de forma totalmente sonora, porém sempre são afetados em algum nível, aberta ou veladamente, por informações não sonoras, incluindo as qualidades semânticas, espectro-morfológicas, visuais ou cinestésicas. (NANCE, 2007, p.16 apud ALIEL et al., 2018, p.170).

Neste contexto, optei por desenvolver um estudo baseado nos relatos e experiências do grupo, tendo como fundamento a noção de produção de presença desenvolvida pelo filósofo, historiador e professor de literatura comparada Hans Ulrich Gumbrecht. Este conceito foi trazido como elemento provocador da prática das/os musicistas que participam, semanalmente 4 das sessões de LIM da Orquestra Errante, tendo como objetivo tensionar a reflexão acerca das oscilações de efeitos de sentido e efeitos de presença(GUMBRECHT, 2010, p.22) que podem ser estabelecidas durante este tipo de performance e proporcionar debates sobre a experiência estética associada à presença física e/ou virtual em práticas artísticas cuja materialidade é o som.

Com isso, configurei um recorte metodológico relacionado à pesquisa empírica e às vivências singulares de cada pessoa, o qual não poderia ser condicionado por uma epistemologia puramente hermenêutica ${ }^{5}$. Ao conceber a proposta, segui portanto, uma das principais substâncias do pensamento gumbrechtiano, o qual

[...] defende o riskful thinking, aproximadamente pensamento arriscado [...] Segundo Sanford (2000, p. 1), em face desse pensamento, Gumbrecht reconhece que o papel da academia é 'manter viva a complexidade sublime', pelo movimento heurístico, visando '[...] perseguir ideias [sic] e realizar pesquisas que não [produzam] apenas uma ou algumas respostas fáceis, mas geralmente novos questionamentos'. Nessa perspectiva, de modo geral, sua filosofia abre-se como possibilidade à diversidade epistemológica (SILVA, 2017, p.506).

Tendo esta concepção como referência, a proposta performativa apresentada às/ aos musicistas da OE configurou-se metodologicamente a partir do pensamento apresentado em uma obra teórica que prioriza o desenvolvimento de uma nova epistemologia, a qual intenciona desestabilizar a noção que temos sobre o sentido nas relações humanas e com as coisas do mundo 6 .

Ao arriscar-se na relação interdisciplinar e com uma teoria que tangencia a área

4 Os encontros da Orquestra Errante acontecem toda quinta-feira das $17 \mathrm{~h}$ às $20 \mathrm{~h}$ no Departamento de Música da Universidade de São Paulo.

5 Essa noção é exposta em diversos trechos de Produção de Presença. Para Gumbrecht sua obra assume o compromisso de lutar contra a dimi- nuição sistemática da presença e contra a centralidade incontestada da interpretação nas disciplinas do que chamamos 'Artes e Humanidades' (GUMBRECHT, 2010, p.15). Além disso, o conteúdo do livro pretende se afastar da escola puramente hermenêutica que no discurso das Huma- nidades estão protegidos por gestos de intimidação intelectual (GUMBRECHT, 2010, p.80). 0 autor coloca também que ao tentarmos encontrar um modo de definir [as] 'materialidades da comunicação' e estabelecer quais os instrumentos mais adequados para analisá-las, fomos obrigados a pensar nas Humanidades, tal como existiam (e ainda hoje, na maioria dos casos, existem), como uma tradição epistemológica que, ao longo de mais de uma século, nos mantivera à margem de tudo que não podia ser descrito como, nem transformado numa, configuração de sentido (GUMBRECHT, 2010, p. 120).

6 Segundo Grumbrecht uma das maneiras de se perceber a produção de presença é a partir do impacto que as coisas do mundo causam em nós: E não desejamos precisamente a presença, não é o nosso desejo de tangibilidade tão intenso, por ser o nosso ambiente cotidiano tão quase in- superadamente centrado na consciência? Em vez de termos de pensar sempre e sem parar no que mais pode haver, às vezes parecemos ligados num nível da nossa existência que, pura e simplesmente, quer as coisas do mundo perto da nossa pele (GUMBRECHT, 2010, p.135). 
musical, este estudo tem a intenção de compreender a necessidade da concretude da presença física em processos de criação em tempo real e o impacto dos sons executados em um mesmo espaço acústico, comparando-os à representação bidimensional da imagem virtual e aos sons remotamente produzidos.

Vale também mencionar que a intenção deste estudo não é discutir a implementação de ferramentas de transmissão sonora ou a difusão de novas tecnologias para interação artística, mas tentar compreender a expressividade e a comunicação humana elaborada através de aparatos comuns da telemática e problematizar como a atual naturalização das relações virtuais se propaga nos discursos poéticos ao compararmos processos de criação musical realizados em ambientes virtuais com atuações musicais elaboradas simultaneamente em espaços concretos.

Logo, compete ao estudo provocar uma reflexão sobre o que vem a ser a presença7 e as oscilações entre efeitos de sentido e efeitos de presença colocadas por Gumbrecht a partir das relações intersubjetivas do grupo de livre improvisadoras/es, as/os quais apresentaram relatos que não se encerram em si mesmos, promovendo a construção de conhecimento, por vezes, distante das correntes da área musical estrita.

\section{Sobre produção de presença e a concepção da proposta performativa}

Segundo Gumbrecht, após o Iluminismo, influenciado pelo pensamento cartesiano, o ser humano passou a relacionar-se com o mundo a partir de uma perspectiva hermenêutica, baseada no sentido e no significado que podemos dar ao que nos rodeia. Em sua concepção, o autor explora a ideia de que,

Se atribuirmos um sentido a alguma coisa presente, isto é, formarmos uma ideia do que essa coisa pode ser em relação a nós mesmos, parece que atenuamos inevitavelmente o impacto dessa coisa sobre o nosso corpo e os nossos sentidos (GUMBRECHT, 2010, p.14).

Partindo de análises históricas, culturais e filosóficas, Gumbrecht sugere que concebamos a experiência estética como uma oscilação/tensão (às vezes uma interferência) entre efeitos de presençae efeitos de sentidoepropõeque a presença se dêa partir de relações espaciais e vê a palavra produção com o significado trazer para adiante. Portanto, coloca os objetos, as coisas do mundo, como mediadores destas relações:

Se 'producere' quer dizer literalmente, 'trazer para adiante', 'empurrar para frente', então a expressão 'produção de presença' sublinharia que o efeito de tangibilidade que surge com as materialidades de comunicação é também um efeito em movimento permanente. (GUMBRECHT, 2010, p.38).

7 Neste sentido, a ideia de presença cênica pesquisada há décadas no âmbito das Artes Cênicas e pouco discutida na área da Música se conec- taria com a proposta por inserir uma noção corporal e performativa diferente da qual as/os musicistas, em sua maioria, não estão habituadas/os. 
À luz desta concepção sobre a presença, passei a analisar relações performativas mediadas por dispositivos das novastecnologias, tais comocomputadores, plataformas de comunicação virtual ou gravações de áudio que auxiliam a/o musicista a estudar sobre determinados padrões rítmico-harmônicos - como é o caso dos play alongs ${ }^{8}$ - , mas que, ao mesmo tempo a/o impedem a afecção de seu/sua interlocutor/a por este/a utilizar (ser) uma gravação preconcebida e não estar presente no mesmo espaço físico que a/o performer que está tocando sobre a gravação.

É importante ressaltar que, nestes tipos deperformance, embora haja dispositivos eletrônicos mediando as relações sonoras, não se pode esquecer que o corpo da/o performer como um todo é, desde o princípio, o mediador de qualquer relação que se estabeleça musicalmente equeestamos diantedemáquinas ou tecnologias virtuaisque podem servir como amplificação e restabelecimento das conexões do ser humano com o mundo, como aponta o pesquisador e compositor Fernando Iazzetta:

Deve-se [...], entender o desenvolvimento das máquinas como um modo de se criar interfaces entre as dimensões do corpo e as dimensões do ambiente. Nesse sentido, a máquina deixa de fazer uma remissão ao inumano para colocar-se como conexão do humano com seu ambiente: as máquinas possibilitam a projeção das ações do homem na dimensão do ambiente, amplificando, estendendo, ou acelerando essas ações (IAZZETTA, 2009, p.82).

No entanto, considerando as "categorias perceptivas ecomportamentais voltadas para atividades como exploração, seleção, foco de atenção e ações e interações com o mundo" (REYBROUCK apud IAZZETTA, 2009, p.78) instituídas pelos seres humanos, nem sempre teremos as máquinas como elementos catalisadores de produção de presença no ato performativo.

É possível utilizar como exemplo o problema que envolve situações performativas como peças de teatro ou concertos musicais que, gravadas e posteriormente apresentadas em vídeo, parecem perder sua potência e/ou seu impacto cênico, sendo quase que destituídas de suas qualidades vinculadas à presença.

Impulsionado por estas questões, me propus a observar onde e como se instaura a produção de presença na LIM a partir da proposta performativa a ser executada pela Orquestra Errante em dois encontros subsequentes realizados entre os meses de maio e junho de 2018. Durante o processo de pesquisa, observei as comunicações mediadas pela internet que se fraccionam, por conta de problemas com a latência, softwares ou hardwares das máquinas, o que, irremediavelmente, nos coloca diante de diálogos intermitentes ou de situações de ausência de comunicação.

A proposta, no entanto, não tinha como objetivo restringir a inventividade e empirismo técnico-sonoro das/os performers, mas aplicar o que tenho chamando de mol-

8 Play alongs que em em português pode ser traduzido como acompanhar, cooperarou mesmo fazer algo que alguém disse para fazê-/o, são também gravações de músicas, normalmente do gênero popular, as quais têm sempre um dos instrumentos da versão original suprimido para que $o$ instrumentista/cantor possa estudá-las, simulando em tempo real a prática com outras/os musicistas. 
duras poéticas durante minhas proposições para a OE. Deste modo, desenvolveria um contexto diferente do ambiente de criação rotineiro do grupo a partir da inserção de alguns direcionamentos para as sessões de improvisação, em função de uma reflexão sobre as performances, das relações entre musicistas e de discussões posteriores sobre a noção de produção de presença.

Os direcionamentos iniciais da proposta foram sugeridos ao grupo uma semana antes dos dois encontros em que a executaríamos ${ }^{9}$ e nos quais conversaríamos sobre os desdobramentos das sessões de improvisação.

Neste primeiro momento, optei por não explanar sobre as referências e os objetivos da proposta em razão das diretrizes serem bastante simples e porque os procedimentos de minhas pesquisas tentam seguir, na medida do possível, uma metodologia que se vincula à ideia de experiência segundo o que afirma Jorge Larrossa. O professor de filosofia da educação a define como tudo "o que nos passa, o que nos acontece, o que nos toca" (LARROSA, 2014, p.18), defendendo que o simples fato de termos informações a respeito do que vivenciaremos nos distancia do estado de experiência.

Para que melhor se compreenda as discussões a serem elaboradas neste texto, apresento abaixo as diretrizes da proposta lançada às/aos musicistas que integram ${ }^{10} \mathrm{a}$ Orquestra Errante:

Parte I (primeira semana)

1 - Formar um duo com outra pessoa do grupo e gravar sozinha/o um solo de, no máximo, 10 minutos;

2 - Enviar o solo gravado para sua dupla por e-mail, Whatsapp, Wetransfer etc. durante a semana que antecede o encontro do grupo;

3 - Improvisar, em casa, sobre a gravação recebida (IMPORTANTE: não ouvir o solo antes de improvisar. Aperte play e saia ouvindo/tocando);

4 - Relatar, durante o encontro semanal do grupo, como foi a experiência.

\section{Parte II (segunda semana)}

1 - Durante o encontro semanal do grupo, formar duos, de preferência, diferentes daqueles que se formaram para a primeira parte da proposta;

2 - As/os integrantes do duo devem estar conectados à internet em salas diferentes $^{11}$ e improvisar com a/o outra/o por, no máximo, 10 minutos ${ }^{12}$;

\footnotetext{
9 A primeira pessoa do plural será muitas vezes conjugada ao longo do texto porque, como membro da Orquestra Errante há três anos, também participei da proposta criada por mim e por ter me envolvido nas discussões sobre as sessões de improvisação e sobre a teoria desenvolvida por Gumbrecht.

10 Nas duas semanas em que a proposta foi elaborada, estiveram presentes nos encontros 18 musicistas, sendo que todas/os relataram, em pelo menos um dos encontros, suas experiências para o grupo: Caio Righi, Rogério Costa e César Martini(saxofones), Fabio Martinelli (trombone), Miguel Antar (contrabaixo) Paola Pickerzy e Guilherme Beraldo (violões), Fabio Manzione (bateria e percussão), Cassio Moreira (percussão), Stênio Biazone Inês Terra(voz), Marina Mapurunga e Flora Holderbaum (violinos), Nanati Francischini, Denis Abranches e Pedro Sollero(guitarras) Tiago Azevedo (flauta transversal) e Mariana Carvalho (piano).
}

11 No momento, dispúnhamos de duas salas do Departamento de Música da Universidade de São Paulo e seus respectivos computadores e caixas de som.

12 As limitações de tempo da proposta serviram apenas para que fosse possível todas/os improvisarem e relatarem suas experiências dentro do período de encontro do grupo. 
3 - Relatar, após as sessões de todos os duos terem sido elaboradas, como foi a experiência e que reflexões pôde fazer sobre essa maneira de improvisar.

Para fazer confluir minhas reflexões acerca da presença e o contexto criativo da OE, desenvolvi a proposta performativa com o objetivo de criar mecanismos que, premeditadamente, provocassem a sensação da ausência espacial de instrumentos e instrumentistas no intuito de, em performances presenciais futuras, potencializar a produção de presença e o impacto das coisas do mundo sobre as/os improvisadoras/es.

Ao propor a utilização desses recursos artificiais ${ }^{13}$ para mediar as performances de LIM do grupo, também busquei mensurar o que nas relações entre as/os musicistas advém do âmbito sonoro, o que é visual, o que pertence às condições espaciais onde se encontram musicistas improvisadoras/es, ou mesmo o que pode estar ligado a outros sentidos do corpo humano.

Para fomentar as discussões sobre as sessões de LIM formulei cinco perguntas, as quais expus aos integrantes do grupo ao término da segunda parte da proposta, seguindo a ordem em que elas se encontram a seguir:

1) A utilização de ferramentas amplamente difundidas para o estudo da improvisação idiomática, como é o caso dos play along, funciona para a prática da LIM?

2) A "presença sendo a corporificação de algo" (GUMBRECHT, 2010, p.167), como chegar ao estado de presença?

3) A improvisação mediada pela internet e/ou por gravadores de áudio nos faz sentir a falta física do outro?

4) Afiltragem sonora evisual produzida por aparelhos eletrônicos/mídias virtuais nos impede de "corporificarmos" a presença, o impacto que o outro ou as coisas do mundo nos causa?

5) As mídias virtuais eliminam, amenizam ou restauram a produção de presença?

\section{Relatos individuais e reflexões coletivas ${ }^{14}$}

Após a primeira parte da proposta ter sido elaborada, cada dupla relatou suas dificuldades, expectativas e esforços para improvisar livremente a partir das gravações recebidas, ressaltando peculiaridades e características de cada sessão. Comento, nos parágrafos seguintes, algumas citações/situações paradigmáticas dessa experiência e as avaliações feitas pelas/os integrantes do grupo em seus relatos.

Vale mencionar que nessa primeira parte da proposta as/os integrantes do grupo ainda não tinham tomado conhecimento das perguntas elencadas acima, as quais fo-

\footnotetext{
130 termo "artificiais" é utilizado em virtude das sessões de livre improvisação da Orquestra Errante ocorrerem, quase sempre, de forma presencial.

14 É possível ouvir os relatos e debates sobre a proposta em sua versão integral acessando os links abaixo: https://soundcloud.com/duocoz/ relatos-e-reflexoes-coletivas-dia-1 https://soundcloud.com/duocoz/relatos-e-reflexoes-coletivas-dia-2
} 
ram apresentadas somente após as últimas sessões de improvisação da segunda parte da proposta.

Inicialmente, durante os relatos das/os musicistas da OE surgiram questões sobre o funcionamento dos dispositivos de áudio e as dificuldades em lidar com a proposta durante a semana por conta de compromissos externos ao grupo ou mesmo para se comunicar com as/os parceiras/os de improvisação. Em seguida, passaram a "tomar conta" dos relatos comentários sobre a formulação de situações hipotéticas anteriores à improvisação em si, o que, para além de divergir da proposta e de ter afastado alguns/ as dos/as improvisadores/as do ato de improvisar com a gravação de sua/seu parceira/o, colocou as/os performers diante de um dilema temporal: pensar a performance em tempo diferido e planejar o que será tocado ou vivenciar em tempo real o que está por vir, permitindo que os devires da improvisação estabeleçam relações entre os performers?

Estes questionamentos parecem ter ocorrido não somente antes das performances, mas também durante as mesmas, gerando no/a improvisador/a oscilações entre momentos de pura reflexão sobre o fazer (efeitos de sentido) e momentos de interação e imersão(efeitos de presença).

Outro aspecto importante a ser destacado é a ideia de que não é possível elaborar uma performance de LIM a partir de uma gravação, sem a presença em temporeal da/o outra/o. Esta noção foi colocada por Inês Terra ${ }^{15}$ e Guilherme Beraldo ${ }^{16}$ ao fazerem os relatos de suas sessões com o play along enviado pelas/os parceiras/os. Com essas palavras, inauguram-se na discussão as falas sobre a presença e a ausência do outro durante as improvisações elaboradas a partir das gravações de áudio, e as/os improvisadoras/es passam a discorrer sobre "o não poder afetar a/o outra/o", por estes não estarem no mesmo espaço físico, sobre o "tocar em cima" da/o outra/o e até mesmo sobre um caráter diretivo da proposta, considerando que as práticas da OE são de livre improvisação.

Nesse sentido, a provocação inicial colocada aos performers parecia estarfazendo efeito instaurar a ausência para propiciar desejo de presença, gerando um incômodo útil para o que ocorreria na semana seguinte. Por outro lado, a frase também trouxe à consciência o fato de que, para contrabalançarmos a ausência do outro, quase sempre nos colocamos a imaginar os gestos corporais, a posição espacial, os timbres que o outro normalmente faz quando presente. Ou seja, em decorrência da não presença física de outra/o performer com quem se está improvisando, se recria a imagem e os movimentos da/o outra/o no intuito de improvisar a partir do que pode vir a ser a imagem daquela/e parceira/o executando um determinado som ou gesto musical, tornando a performance diante da gravação quase que um ato de adivinhação de sonoridades e de gestos corporais emusicais.

Uma performance que, pela ausência da/o outra/o se torna reflexiva, em ambos os sentidos do termo, comprova o fato de que também improvisamos dentro de um

15 Inês Terra é mestra em Música pela Universidade de São Paulo e integra a Orquestra Errante como cantora.

16 Guilherme Beraldo é graduando em Música pela Universidade de São Paulo e integra a Orquestra Errante como violonista. 
estado de confluência com nossa imaginação e memória, como afirma o pesquisador e músico Manuel Falleiros:

[...] na improvisação, de maneira geral, a memória e o imaginário são elementos de importância e envolvidos diretamente na criação, mas eles apenas se tornam ativos e direcionados para este fim quando requeridos pelo momento da ação criadora. (FALLEIROS, 2012, p. 50).

Imaginação e memória, normalmente, podem ativar processos mais associados a aspectos técnicos e sonoros em momentos de criação, entretanto nas sessões instauradas pela proposta, o ato de imaginar esteve, quase sempre ligado à intenção de perceber os gestos físicos da/o outra/o, enquanto a memória parecia buscar ideia pregressa ou futuras sobre a/o outra/o e quais seriam suas ações em tempo presente. Ou seja, pareciam se ater mais a relações externas do que internas. A existência deste tipo de intenção foi relatada por Marina Mapurunga ${ }^{17}$ e Mariana Carvalho ${ }^{18}$ em diferentes momentos das discussões sobre a proposta:

O que eu senti é que no começo não tinha muito espaço para mim, aí eu ficava 'nossa, gente como foi que ele fez isso?!' Eu fiquei tentando imaginar como ele tava fazendo aquele som. Aí eu, 'gente, isso aqui deve tá editado, não acredito!' Depois queria até saber se é ou não. Nossa, uma coisa assim atrás da outra, eu não conseguia, eu entrava, mas eu me sentia meio que intimidada até porque eu não tava me escutando bem.

Acho que isso de você ficar pensando os lugares que você imagina que a outra pessoa vai tocar, assim, tipo, por mais que eu tenha feito para o César eu também sabia que podia ser para outras pessoas, sei lá, que eu podia mandar para outras pessoas, sei lá, então eu também pensei em tocar imaginando que teria buracos ou coisas para as outras pessoas tocarem.

Na segunda parte da proposta (segunda semana), após as duplas terem improvisado mediadas pelas plataformas de comunicação virtual ${ }^{19}$, li trechos do livro de Gumbrecht $^{20}$ e as cinco perguntas relacionadas ao tema para dar início aos relatos e discussões sobre as recém- executadas sessões de livre improvisação.

Diferentemente da semana anterior, neste dia, a exposição dos relatos/reflexões se deu de forma aleatória, não seguindo uma ordem linear a partir da organização de execução de cada uma das duplas. Seguindo este critério, as descrições neste trecho não estão agrupadas exatamente como aconteceram durante as conversas, mas a partir da quantidade de ocorrências de cada tópico discutido e/ou de sua relevância para a pesquisa.

17 Marina Mapurunga é doutoranda em Música pela Universidade de São Paulo e integra a Orquestra Errante como cantora e violonista.

18 Mariana Carvalho é graduada em Música pela Universidade de São Paulo e integra a Orquestra Errante como pianista.

19 Neste dia da proposta, utilizamos dois notebooks ligados à caixas de som e à plataforma de comunicação virtual Google Meet/Hangouts.

20 Produção de Presença: o que o sentido não consegue transmitirde Hans Ulrich Gumbrecht. Rio de Janeiro: Ed. PUCRio, 2004. 
A segunda parte da proposta, em comparação com a primeira, dispunha de uma nova materialidade, os estímulos visuais emitidos pelas telas dos notebooks presentes nas duas salas em que ocorreram as sessões de improvisação. Por esse motivo a discussão se iniciou tendo como temáticas a demasiada valorização do sentido da visão na atualidade, a característica bidimensional da imagem e a tentativa das mídias virtuais de reproduzirem os fluxos de acontecimento da vida real.

A hipervalorização do sentido da visão nas culturas ocidentalizadas extrapola os contextos das relações sociais, podendo também estar imbricada a relações estéticas como performances de LIM. Assim, nossa construção de conhecimento está intimamente atrelada à visão, chegando esta a se sobrepor aos demais sentidos ${ }^{21}$ humanos e, muitas vezes, a servir como principal fonte de apreensão da realidade, como afirma a antropóloga Silvia Caiuby Novaes:

De todos os sentidos, é à visão que atribuímos um valor privilegiado. A associação entre olhar e conhecimento pode ser percebida em alguns indícios, como o nome de várias revistas de informação: Veja, Visão, Nouvel Observator, Vu, Look etc. (NOVAES, 2009, p.38).

\section{$[\ldots]$}

Nesse sentido, uma outra conquista desse privilegiamento da visão é que as imagens que produzimos acabaram por dominar nosso cotidiano, chegando mesmo a substituir a experiência. (NOVAES, 2009, p.40).

Em virtude desta hipervalorização do sentido da visão ${ }^{22}$, temos cada vez mais ampliada a carga de estímulos gerada por dispositivos de comunicação telemática, como aparelhos celulares e notebooks. A influência deste contexto comprovou-se nasperformances das/os integrantes da $\mathrm{OE}$, demonstrando a necessidade do sentido da visão nas sessões de LIM realizadas por meio de mídias virtuais, o qual atuou significativamente sobre a prática de uma expressão artística que tem o som como principal materialidade. A partir disso, surgiram as questões sobre quais informações ou presenças são transmitidas pela imagem do corpo, seja ela concreta ou virtual, que poderiam interferir no som que será emitido por quem a vê.

As comparações entre improvisações presenciais e virtuais são inevitáveis, tendo em vista que é quase impossível dizermos que a presença física do outro não nos traz algo de impactante, ou que, quando em frente a uma tela temos como dimensionar perfeitamente os espaços em que a/o outra/o e seu som estão operando. Em frente à

21 Mesmo entre musicistas e músicos pude verificar discursos impregnados de analogias entre a percepção do que é visual e do que é sonoro, comprovando uma hegemonia do sentido visual sobre o auditivo mesmo quando nos referimos oralmente sobre a materialidade do fazer musical. Expressões como "aumentar o Caio (nome de um dos músicos participantes da proposta)", "projetar o som" e "eu tenho um recurso que ele não tem do ponto de vista acústico" denotam um discurso impregnado de verbos e termos em que o sentido da visão parece prevalecer sobre o da escuta, fazendo com que o significado do "ouvir" seja incorporado pelo ato de "ver" oque tam bém acaba por comprovar as transversalidades entre os sentidos humanos e como as naturalizamos.

22 Os estudos da antropóloga não se limitam à atualidade. 0 privilegiamento do sentido da visão e sua relação com o conhecimento figuram como um aspectos culturais que vem sendo construídos há secúlos pelas sociedades ocidentalizadas. A própria autora comprova e $m$ outro trecho do mesmo artigo: "Na segunda metade do século XIX, com a invenção das novas tecnologias para reprodução de imagem como fotografia e, posteriormente, o cinema há uma clara associação entre olhar e conhecimento" (NOVAES, 2009, p.38). 
tela que produz apenas imagens em duas dimensões deixamos de poder utilizar nossa percepção espacial, o que tenho chamado de soslaios do $\operatorname{corpo}^{23} \mathrm{e}$, ao mesmo tempo de sofrer o "impacto das coisas do mundo" (GUMBRECHT, 2010, p.14) sobre nós. No caso da improvisação em duplas via internet, os soslaios do corpo de cada performer deixariam de perceber o som da/o outra/o e do espaço reverberando da mesma forma, já que cada um/a esteve em espaços diferentes durante suas respectivas improvisações. O mesmo ocorreria com a relação a ser estabelecida entre uma/um musicista e o instrumento musical, o gesto físico e o corpo da/o outra/o performer.

Importa também considerar que, apesar da percepção não ser "uma soma de dados visuais, tatéis ou auditivos"24 (MERLEAU-PONTY 1969, p.105 apud NOVAES, 2009, p. 40) e de percebermos o mundo de maneira não segmentada, em muitas situações, a hierarquização dos sentidos que existe em nossa sociedade nos faz inconscientemente direcionar a atenção para sentidos que não necessariamente são os "decodificadores" das materialidades da expressão artística em questão. O que não se configuraria como um problema para processos de criação sonora em tempo real, consolidando assim a relevância do aspecto visual para a performance musical como meio de propagação e reverberação de devires do corpo e de intenções sonoras.

Por esse ângulo, o caráter mais visual desta segunda parte da proposta corrobora a ideia de que o efeito de presença se dá necessariamente a partir de uma relação espacial, e não somente temporal, já que, para algumas/uns integrantes da OE improvisar através da tela de um computador pareceu algo artificial, não permitindo que as interferências acústicas do espaço da/o outra/o nem seus gestos físicos pudessem impactar diretamente a produção dos sons das/os respectivas/os parceiras/os de sessão. Apesar disso, as performances de LIM - expressão artística que se desenvolve, necessariamente, a partir do som e sua espacialização - não deixaram de acontecer.

Por outro lado, as/os outras/os integrantes do grupo que acreditam ter se comunicado plenamente através dos sons não viram a necessidade de se sentirem impactadas/ os diretamente/presencialmente por sons não mediados por caixas de som nem pelos gestos corporais tridimensionais da/o performer que estava improvisando em outra sala. Isto, talvez em virtude da naturalização da difusão sonora por meio de amplificadores e caixas de som e de uma hipervalorização do sentido da visão.

Esse dilema levou-nos também a uma análise da representação do sujeito pelas mídias virtuais e ao fato de estarmos nos acostumando a perceber as relações humanas via internet como idênticas às reais. A partir dessas colocações, Caio Righi ${ }^{25}$ citou o filósofo checo Vilém Flusser (1920-1991), que nos fala sobre a imagem como primeira tentativa do ser humano de dar sentido a algo externo a si mesmo e da imagem técnica,

23 A metáfora elaborada durante o processo de criação da proposta faz menção às percepções que se tem do espaço e do outro a partir da atenção no ambiente e dos reflexos corporais conectados às ações/intenções de quem está fisicamente no mesmo espaço, sem que seja necessário estar virado de frente ou extremamente próximo ao sujeito da ação que está por vir ou que já se iniciou. Soslaios do corpo também pode ser interpretado como um estímulo aos reflexos corporais que são ativados pela escuta ou pela escuta que é acionada por ações corporais.

24 A percepção não é uma soma de dados visuais, táteis ou auditivos: percebo de modo indiviso, mediante meu ser total, capto uma estrutura única da coisa, uma maneira única de existir, que fala simultaneamente a todos os meus sentidos. (MERLEAU-PONTY 1969, p.105 apud NOVAES, 2009, p.40).

25 CaioRighiégraduado em Artes Visuais pela Universidade de São Pauloe integrou a Orquestra Errantecomo saxofonista eflautista. 
aquela produzida pelas câmeras fotográficas e telas de cinema, que por conta de seu "caráter aparentemente não simbólico, objetivo [...] faz com que seu observador as olhe como se fossem janelas e não imagens"26 (FLUSSER, 1985, p.10).

Assim, vimos que a tentativa de tornar real aquilo que não é também comprova as limitações imagética, espacial esonora do dispositivo quetransmite a plataforma de comunicação virtual enos reporta novamente à ideia de que épossível projetar a presença do outro e escolher a partir de ideias provenientes de interações sonoras pregressas ou da imaginação para se improvisar. Esforçamo-nos, portanto, para perceber a imagem na tela como algo real, mas que ainda deve ser "completado" em razão da falta de presença física da/o performer com quem se está tocando. Com isso, nos submetemos a idealizar o que está acontecendo "do outro lado", a considerar a representação como algo real e a tentar intuir o som/gesto da/o outra/o performer.

Em parte, é possível comprovar essa situação no relato de Stênio Biazon ${ }^{27}$ :

Há uma leitura representativa da coisa no sentido de que eu estou ouvindo esse som aqui da 'caixinha' unidirecional . . . faltam várias frequências, não ocupam espaço do mesmo jeito. No entanto eu sei, pelo meu costume com gravação e por eu conhecer a situação que ele é um som mediado, ele é um som acusmático.

Ademais, os sons atravessam esse contexto de uma maneira ainda mais sutil e difícil de avaliar da mesma maneira que a imagem por vários motivos. Em primeiro lugar, a improvisação mediada por caixas de som é uma prática muito comum entre as/ os performers da $\mathrm{OE}$; isto ocorre pois instrumentos não acústicos são utilizados com frequência pelo grupo, mesmo em ensaios não mediados por plataformas virtuais. Em segundo lugar, a escuta musical trabalhada no grupo, que busca não se privar de nenhuma qualidade timbrística, seja ela ruidosa ou não, é acostumada a não considerar a mediação por dispositivos elétricos, como caixas de som/amplificadores, como algo que prejudicaria a performance ou que diminuiria a atenção da/o performer. Portanto, esta ferramenta não causaria, em sessões remotas, o desejo de presença do outro.

Um terceiro ponto a ser considerado é uma crença por parte das/os musicistas de que a utilização da visão é necessária apenas em poucos instantes da performance musical, o que pode tornar pouco precisa a mensuração do quanto se está imaginando/ projetando da relação com a/o outra/o quando se limita o campo visual durante uma improvisação mediada por dispositivos de comunicação telemática.

No entanto, em razão dos sons não possuírem, ao menos não em sua origem, um caráter simbólico preponderante, como a palavra ou a imagem, e permitirem interpretações mais subjetivas sobre suas qualidades, parece ter sido indispensável por parte

26 “O caráter aparentemente não-simbólico, objetivo, das imagens técnicas faz com que seu observador as olhe como sefossem janelas e não imagens. 0 observador confia nas imagens técnicas tanto quanto confia em seus próprios olhos. Quando critica as imagens técnicas (se é que as critica), não o faz enquanto imagens, mas enquanto visões do mundo. Essa atitude do observad or face às imagens técnicas caracteriza a situação atual, onde tais imagens se preparam para eliminar textos. Algo que apresenta consequências altamente perigosas. A aparente objetividade das imagens técnicas é ilusória, pois na realidade são tão simbólicas quanto o são todas as imagens" (FLUSSER, 1985, p.10). 
das/os musicistas que seus relatos sobre as performances de LIM também fossem baseados em um aspecto sensorial mais objetivo como a visão.

\section{Considerações finais ${ }^{1}$}

A colheita de depoimentos de cada membro acerca do conceito de produção de presença e de sua aproximação da prática da LIM ampliou o escopo de minhas análises e problemáticas e, em algumas situações, ajudou a desconstruir determinadas ideias sobre o conceito concebido por Gumbrecht quando vinculado a processos de criação sonora em temporeal.

No entanto, durante as discussões acerca da presença, não se chegou a um consenso sobre como os dispositivos mediadores - gravadores de áudio e plataformas de comunicação virtual - capacitam ou incapacitam a percepção das/os performers durante as sessões de livre improvisação. Ademais, talvez tenhamos chegado a tantos impasses durante nossas reflexões em função dos fatores subjetivos presentes em processos artísticos de criação.

Em virtude disso, surgiram outras perguntas sobre o tema: a presença deve ser mensurada a partir da relação que se estabelece com o outro ou é medida a partir do que cada um avalia sobre sua presença? É necessário um observador externo para avaliar as situações de um possível estado de presença de cada performer?

O principal impedimento para que estas perguntas não tenham sido respondidas com propriedade e para que a oscilação entre efeitos de presença e efeitos de sentido não pudesse ser avaliada de maneira exata e segmentada - considerando os relatos individuais das/os envolvidas/os - é o fato desta ocorrer de maneira fluida e efêmera durante as performances de LIM.

Além disso, o fato da música não ser consituída por sons que possuam um significado simbolicamente mais objetivo, por si só, configura-se como um entrave às perguntas trazidas à OE. Como compreender os efeitos de sentidoe os efeitos de presença se raramente há um sentido que não seja subjetivo em música?

Em primeiro lugar, durante uma performance musical, o que poderiamos chamar de sentido nem sempre está vinculado ao som propriamente dito, mas, sim a memórias que esse som traz, aos gestos que ele desencadeia ou às imagens que possam ser suscitadas por ele. Isto se deve, em boa parte, pela longa relação que temos com a percepção hermenêutica das coisas do mundo. Em segundo lugar, no decorrer de performances musicais, o suposto sentido pode estar atrelado a situações que não são construídas pelo som diretamente - embora possam estar em função dele - como o gesto corporal de outras pessoas, o olhar da/o outra/o, as condições do espaço (cheiro, cores, temperatura etc.).

Entretanto, apesar de buscarmos com frequência um sentido no que está ao nosso redor, é necessário estar alerta para os momentos em que fazemos isto de fato e para as situações em que permitimos que a busca pelo sentido não atue. Talvez somente desta forma seja possível compreender ou perceber as oscilações entre efeitos de presença e efeitos de sentido. 
Por outro lado, caso existam elementos nomináveis de um fazer musical mais ligado aos efeitos de presença, é importante saber quais seriam as maneiras de percebê-los. O "impacto das coisas do mundo" (GUMBRECHT, 2010, p.14) sobre nós não é traduzível em palavras, mas assumidos pelas afecções, pela porosidade corpórea e pela imersão dos sentidos em estado a não ser compreendido, mas experienciado.

Seguindo esta lógica, dificilmente seria possível afirmar que não há como atingir um estado de produção de presença durante sessões de LIM, sejam elas presenciais ou virtuais. Isto porque ambas podem suscitar oscilações entre efeitos de sentido e efeitos de presença.

No entanto, o fato de haver diferentes tipos de separação espacial entre as/os performers nas duas partes da proposta performativa fez com que algumas/uns sentissem os efeitos de presença alterados por fatores visuais e/ou sonoros e em razão dos diferentes procedimentos e ferramentas utilizados. Além disso, embora nem todas/os tenham concordado sobre como a visualização ou a sonoridade emitida pela/o outra/o por meio dos dispositivos de comunicação telemática afetaram suas performances, ficou evidente que há diferenças entre sessões de improvisação presenciais e virtuais se considerarmos a influência da espacialização sonora, das condições temporais e do gesto físico para cada musicista.

Comparando sessões de LIM presenciais anteriores às considerações apresentadas pelo grupo sobre esta proposta, pude observar que cada tipo de performance pôde fazer com que as/os musicistas se afetassem/impactassem a partir de materialidades de naturezas distintas, tais como: (1) sons distorcidos/filtrados em razão de sua amplificação e difusão mecânica ou sons sem equalização realizada por máquinas, (2) sonoridades unidirecionais (caixa de áudio) ou sonoridades multidirecionais (características acústicas do espaço), (3) visualização frontal/bidimensional da/o outra/o ou vizualização tridimensional da/o outra/o, (4) imaginação de gestos e tentativa de complementar o áudio gravado e representação do real pelas imagens expostas nas telas dos computadores ou visualização total dos movimentos e intenções corporais e sonoras da/o outra/o performer, (5) impossibilidade ou possibilidade de utilização dos soslaios do corpo.

Isto posto, é possível dizer que há diferentes produções de presenças para cada espécie de performance, sejam elas presencias ou virtuais. Neste sentido, a afirmação "tem algumas coisas que não podem ser tomadas como dadas, por exemplo, presença não é corporalização, necessariamente", de Flora Holderbaum ${ }^{28}$, denota que poderíamos configurar um estado de presença mesmo em sessões virtuais de LIM. Também podemos considerar que, tanto para performers quanto para um possível público, haveria momentos mais vinculados a um sentido ou interpretações específicas e situações que se encontram mais conectadas à presença ou às percepções sensoriais como um todo.

Há, no entanto, que ser considerado o número ou as camadas de mediações realizadas nas performances, levando em conta corpo, voz, instrumentos, espaço(s), caixas de som e computadores como elementos que representam essas gradações e que

28 Flora Holderbaum é doutora em Música pela Universidade de São Paulo e integrou a Orquestra Errante como cantora e violinista. 
podem influenciar em uma intenção mais reflexiva (efeitos de sentido), mais oscilante ou mais vinculada à presença (efeitos de presença). Nesse sentido, talvez possamos dizer que em performances contendo todas/os as/os musicistas em um mesmo espaço teremos um menor número de mediações do que se improvisarmos por meio de dispositivos como caixas de som e computadores conectados à internet, sendo que, neste último caso, verificamos duplas ou triplas camadas midiáticas, as quais poderiam gerar mais desejo de presença por representarem uma quantidade maior de mediações se comparadas às performances elaboradas em um mesmo tempo-espaço:

O desejo de presença, que invoquei é uma reação a um mundo cotidiano amplamente cartesiano e historicamente específico que, pelo menos às vezes, queremos ultrapassar. Por isso, não é surpreendente nem embaraçoso que nesse contexto [...] as ferramentas conceituais com que procuramos analisar os vestígios desse desejo de presença, num ambiente carregado de sentido, também sejam orientadas em parte pelo sentido, em parte pela presença. (GUMBRECHT, 2010, p.140).

Embora a expressão musical faça uso de uma materialidade abstrata suas/seus performers não têm como desconsiderar completamente os elementos espaciais e corporais durante um ensaio ou uma apresentação. No entanto, quando se improvisa mediada/o por dispositivos da comunicação telemática, pode haver uma queda no impacto desses elementos sobre a atuação das/os musicistas.

Apesar disso, há também que se considerar a opinião de performers que veem as mediações virtuais como algo que não altera de nenhum modo a produção de presença ou o impacto das coisas do mundo sobre si, como é o caso de Rogério Costa ${ }^{29}$ :

Não é o fato de ter um dispositivo eletrônico mediando a comunicação que faz com que isso [a produção de presença] mude, porque a presença tem a ver com a disposição da/o performer com relação a alguma coisa que está acontecendo.

Esta concepção talvez surja devido ao grande estímulo e utilização das tecnologias de comunicação contemporâneas em performances e relações sociais, as quais, por nos privarem dos elementos da relação presencial, podem vir a potencializar o desejo de estarmos presentes e de nos relacionarmos com intensidade em processos de criação em tempo real, sendo eles mediados ou não por dispositivos, como gravadores de áudio ou computadores.

[...] quanto mais perto estamos de cumprir os sonhos de onipresença e quanto mais definitiva parece ser a subsequente perda dos nossos corpos e da dimensão espacial da nossa existência, maior se torna a possibilidade de reacender o desejo que nos atrai para as coisas do mundo e nos envolve no espaço dele. (GUMBRECHT, 2010, p.172).

29 Rogério Costa é professor do Departamento de Música da Universidade de São Paulo e fundador da Orquestra Errante, na qual atua como saxofonista. 
Relevando as opiniões de musicistas sobre a temática e a proposta performativa criada como pano de fundo para as discussões travadas em dois encontros da OE, vale ressaltar que a pretensão desta pesquisa não é chegar a uma conclusão maniqueísta sobre improvisações mediadas por dispositivos da comunicação telemática e outras que não se utilizam destas tecnologias, tendo uma como pior ou melhor que a outra. Como já dito anteriormente, o objetivo deste estudo tem sido buscar as diferenças que existem entre elas e analisar as ferramentas utilizadas durante suas práticas no intuito de mensurar os efeitos de presença e efeitos de sentido, assim como quando operam as produções de presença entre as/os performers.

Desta forma Gumbrecht também coloca em seus apontamentos que suas concepções não devem ser vistas como um manifesto contra a interpretação dos sentidos ou uma apologia à presença, mas como uma reflexão sobre como temos agido diante das novas tecnologias e como viemos a descorporificar nossas relações com o mundo atualmente.

Este pequeno livro não pretendia de modo nenhum ser um 'panfleto contra' conceitos e contra o sentido em geral, ou contra a compreensão e a interpretação [...]. Minha contribuição marginal [...] é muito mais a de dizer que essa dimensão cartesiana não cobre [...] toda a complexidade de nossa existência, embora sejamos levados a acreditar que o faz. (GUMBRECHT, 2010, p. 175).

Considerando a prática da livre improvisação na atualidade e seus desdobramentos performativos, pode-se dizer que o conceito de produção de presença converge com a noção contingencial elaborada nesse tipo de manifestação artística. Assim, justaposto às performances da Orquestra Errante, incorre em uma reflexão geradora de propostas afinadas com os preceitos fundamentais da LIM, que por sua vez, se configura em contextos de intensa relação com o outro e de imersão na experiência sonora.

A pergunta retórica apresentada no título deste artigo, assim como todas as etapas da proposta realizada junto à $\mathrm{OE}$, suas perguntas e problematizações, tiveram como referência um pensamento que nos leva a descontruir a lógica hermenêutica das pesquisas disciplinares e demonstraram o vasto campo epistemológico que pode surgir do diálogo entre a LIM e as concepções de Hans Ulrich Gumbrecht. Sendo assim, não há aqui a intenção de produzir uma conclusão definitiva ou de construir novas fronteiras entre áreas do conhecimento, mas a de confabular sobre, e quem sabe defender, a ideia de uma não segmentação das ações poéticas humanas.

Em suma, este estudo interdisciplinar buscou levantar hipóteses sobre experiências performativas de LIM em sua aproximação das concepções filosóficas de Gumbrecht, as quais provocaram debates que envolveram as/os participantes da OE no intuito de responder os questionamentos de maneira mais abrangente possível. Para além disso, os relatos apresentados pelas/os integrantes do grupo nem sempre tiveram a intenção de responder a um questionário em sua configuração mais cartesiana - destrinchando cada pergunta de maneira organizada e buscando o certo ou o errado de cada respos- 
ta. O levantamento aqui apresentado é, portanto, antes de mais nada, um apanhado de pensamentos arriscados e subjetivos sobre as possibilidades de colocar em prática conceitos de uma filosofia não preocupada em comprovar-se, mas em provocar-se a perceber outras formas de compreender o pensamento e a ação humana.

\section{Referências}

ALIEL, Luzilei. Perspectivas Teóricas para a Análise das Práticas Criativas Ecocognitivas. In: KELLER, Damián. LIMA, Maria Helena de (ed.) Aplicações em Música Ubíqua Vol. 7. São Paulo: Ed. Annpom, 2018. p. 168 - 207. (Série Pesquisa em Música no Brasil)

BAUMANN, Zigmunt. Tempos líquidos. Rio de Janeiro: Jorge Zahar, 2007.

COSTA, Rogério. Música Errante: o jogo da improvisação livre. São Paulo: Perspectiva, 2016.

FALLEIROS, Manuel. Palavras sem discurso: estratégias criativas na livre improvisação. Tese (Doutorado em Processos de Criação Musical) - Universidade de São Paulo, São Paulo, 2012.

FLUSSER, Vilém. A filosofia da caixa preta. São Paulo:Hucitec, 1985.

GUMBRECHT, Hans Ulrich. A Produção de Presença: o que o sentido não consegue transmitir. Rio de Janeiro: Ed. PUC, 2004.

IAZZETTA, Fernando. Música e Mediação Tecnológica. São Paulo: Perspectiva, 2009.

LAROSSA, Jorge. Tremores: escritos sobre experiência. Belo Horizonte: Autêntica, 2014.

McLUHAN, Marshall. Os meios de comunicação como extensões do homem.São Paulo: Cultrix. 1964.

NOVAES, Silvia Caiuby. Imagem e ciências sociais: trajetórias de uma relação difícil. In: BARBOSA, Andrea et al. (ed.) Imagem-conhecimento: antropologia cinema e outros diálogos. Campinas: Papirus, 2009.

SILVA, Wellington Amâncio da. Hans Ulrich Gumbrecht Leitor de Martin Heidegger: concepção de produção de presença. In: Revista Brasileira de Estudos da Presença, Porto Alegre, v. 7, n. 3, p. 505-522, set./dez. 2017. 


\section{'Notas de fim'}

1 Este artigo, escrito antes do início do período de isolamento social que estamos passando, pode parecer anacrônico diante das inúmeras mudanças causadas pela pandemia do novo coronavírus (SARS-coV-2). Para além das questões de saúde pública, as quais não cabem a este artigo relatar, temos sofrido um impacto ainda maior das novas tecnologias em nosso cotidiano. 0 tempo aparentemente dilatado, o estresse causado pela realização de inúmeras vídeoconferências, a não possibilidade de aglomerações humanas e suas consequências para as artes performativas, a reformulação compulsória do ensino escolar e universitário e até uma transformação do vocabulário oral devidoà ressignificação de nosso espaço-tempo são algumas das situações instauradas nosúltimos meses que impuseram a necessidade de reformulações na comunicação entre as pessoas eque, consequentemente, estenderão esta pesquisa.

Os dispositivos elétricos como extensões do corpo humano - como formulou Marshall McLuhan na década de 1960 -, para além de suas capacidades de ampliar aspectos da comunicação humana, trazem consigo suas deficiências e seus efeitos colaterais. Estas características, por sua vez, podem ser percebidas pelo ser humano em maior ou menor grau dependendo da situação. Nos últimos meses, a necessidade de estarmos isolad os socialmente fez com quenos tornássemos mais dependentes das máquinas oque, invariavelmente, nos colocou em relação mais próxima com estas questões.

Considerando um dos seus efeitos da comunicação telemática, 0 atual momento pode ser visto como 0 auge da descorporeização das relações humanas. A noção de tempos líquidos concebida por Zigmunt Baumann há duas décadas se estabelece hoje com maior intensidade, tornando mais aparente as limitações dos dispositivos que utilizamos para nos comunicar e expressar artísticamente. Isto, apesar da imensa quantidade de novos aplicativos para celulares e softwares que têm atualizado nossas máquinas na tentativa de solucionar os problemas da comunicação remota realizada por meio de aparatos eletrônicos.

Por outro lado, a impossibilidade da relação física em um mesmo espaço, ao tornar-se preponderante, fez com que a intenção presencial e a atenção a/ao outra/o se potencializasse em situações de comunicação virtual sendo ela artística ou não. Sendo assim, as conjunturas associadas à pandemia do novo coronavírus e ao isolamento social vivido nos últimos meses me fizeram formular uma infinidade de perguntas que não poderão ser esclarecidas neste texto em razão da não conclusão dessa situação até o presente e de sua complexidade exigir mais espaço do que o permitido a este trabalho. Apesar disso, exponho aqui alguns destes questionamentos a fim de complementar as hipóteses e problematizações apresentadas anteriormente:

(1) Quanto cada improvisação/comunicação telemática absorve de nossafisicalidade equanto dessa fisicalidadeé necessária para a interação musical em tempo real? (2)A/O performer livre improvisador/a recuperaria, unicamente por meio do som, a tatilidade do encontro artístico com a/o outra/o? (3) Possuirmos a capacidade cinestésica é suficiente para "preencher" a ausência física da/o outra/o artista? (4) Como não naturalizar as situações de comunicação telemática, paradoxalmente adversas e proponentes de novas interfaces à expressão humana? 